\title{
вмJ Global Health Poverty reduction and equity benefits of introducing or scaling up measles, rotavirus and pneumococcal vaccines in low-income and middle-income countries: a modelling study
}

Carlos Riumallo-Herl, ${ }^{1,2}$ Angela Y Chang, ${ }^{1}$ Samantha Clark, ${ }^{3}$ Dagna Constenla, ${ }^{4}$ Andrew Clark, ${ }^{5}$ Logan Brenzel, ${ }^{6}$ Stéphane Verguet ${ }^{1}$

To cite: Riumallo-Herl C, Chang AY, Clark S, et al. Poverty reduction and equity benefits of introducing or scaling up measles, rotavirus and pneumococcal vaccines in low-income and middleincome countries: a modelling study. BMJ Glob Health 2018;3:e000613. doi:10.1136/ bmjgh-2017-000613

Handling editor Sanni Yaya

Received 18 October 2017 Revised 19 February 2018 Accepted 24 February 2018
Check for updates

For numbered affiliations see end of article.

Correspondence to Dr Carlos Riumallo-Herl; riumalloher|@ese.eur.nl

\begin{abstract}
Introduction Beyond their impact on health, vaccines can lead to large economic benefits. While most economic evaluations of vaccines have focused on the health impact of vaccines at a national scale, it is critical to understand how their impact is distributed along population subgroups. Methods We build a financial risk protection model to evaluate the impact of immunisation against measles, severe pneumococcal disease and severe rotavirus for birth cohorts vaccinated over 2016-2030 for three scenarios in 41 Gavi-eligible countries: no immunisation, current immunisation coverage forecasts and the current immunisation coverage enhanced with funding support. We distribute modelled disease cases per socioeconomic group and derive the number of cases of: (1) catastrophic health costs (CHCs) and (2) medical impoverishment. Results In the absence of any vaccine coverage, the number of $\mathrm{CHC}$ cases attributable to measles, severe pneumococcal disease and severe rotavirus would be approximately 18.9 million, 6.6 million and 2.2 million, respectively. Expanding vaccine coverage would reduce this number by up to $90 \%, 30 \%$ and $40 \%$ in each case. More importantly, we find a higher share of $\mathrm{CHC}$ incidence among the poorest quintiles who consequently benefit more from vaccine expansion.

Conclusion Our findings contribute to the understanding of how vaccines can have a broad economic impact. In particular, we find that immunisation programmes can reduce the proportion of households facing catastrophic payments from out-of-pocket health expenses, mainly in lower socioeconomic groups. Thus, vaccines could have an important role in poverty reduction.
\end{abstract}

\section{INTRODUCTION}

In September 2015, leaders across the world adopted the 17 Sustainable Development Goals (SDGs) that will guide international development policy through $2030 .{ }^{1}$ These goals build on the Millennium Development Goals and maintain eliminating poverty as one of the overarching goals in the decades to

\section{Key messages}

What is already known about this topic?

- Vaccines have a large beneficial impact beyond health and provide important returns on investments.

- Scale up of vaccines could have a large role in achieving the Sustainable Development Goals and reducing poverty.

What are the new findings?

- We develop a methodology that evaluates the financial risk protection (FRP) benefits of vaccines across income quintiles, thus adding equity and distributional components to previous evaluations.

- The FRP benefits of vaccines are mostly accrued by households in the lowest income quintiles, thus emphasising the role of vaccines as a pro-poor intervention.

Recommendations for policy

- Including equity components into economic evaluations will allow policy makers to opt for interventions that target specifically the most vulnerable populations.

- Comparisons across interventions can now be done by integrating fairness arguments by which groups they impact more.

- Vaccines represent a valuable pro-poor intervention that not only improves health but also protects poor households from catastrophic and impoverishing health expenditures.

come, for example, SDG1 of 'ending poverty in all its forms everywhere'. According to current estimates, approximately 800 million people still live in extreme poverty, and one in five individuals in developing regions is considered extreme poor, that is, living on less than $\$ 1.90$ (2011 Purchasing Power Parity, PPP) a day. ${ }^{2}$ Furthermore, it was 
estimated that over 150 million people annually suffer from catastrophic costs when paying for their family's healthcare between 1990 and 2003. ${ }^{3}$ These estimates and current population growth in these regions emphasise the magnitude of the challenge of eradicating poverty by 2030 represents. Furthermore, this highlights the need for evidence-based policy making that identifies areas where larger benefits can be attained.

One area that has gained impetus as a cause of poverty and financial hardship is healthcare expenditure. A number of studies have identified that out-of-pocket (OOP) healthcare payments are important predictors of financial hardship and poverty. ${ }^{3-6}$ The importance of healthcare payments as a cause of financial hardship was acknowledged by world leaders when establishing financial risk protection (FRP) as one of the targets within the goal of universal health coverage (UHC) including measures against catastrophic health expenditures and medical impoverishment due to health. ${ }^{7-9}$ In particular, this is true for lower-income households that are often at greater risk from experiencing catastrophic health expenditures-health expenditures surpassing a certain threshold of total consumption expenditures or income. ${ }^{10}$ This not only highlights the role of healthcare payments in increasing catastrophic health costs (CHCs) but also generates an explicit link between the goals of eradicating poverty and UHC. Consequently, there is a need to identify both health and non-health interventions that can ultimately contribute to reducing healthcare expenditure (increasing FRP) and the incidence of poverty.

One set of health interventions with particularly great potential is vaccination due to its preventive nature and usually lower cost compared with treatment. In May 2012, the World Health Organization (WHO) Global Vaccine Action Plan highlighted vaccinations as essential tools for improving individual-level health globally. ${ }^{11}$ The widespread attention that vaccines have received during the last decade, such as the public endorsement from WHO member states of the Global Vaccine Action Plan, highlights the role that vaccines can play in the broader development agenda. However, despite overwhelming evidence on their efficacy and health impact, the rather limited evidence on their broader distributional economic benefits may constrain their expansion in low-income and middle-income countries that see some vaccines as relatively expensive, especially when many governments are resource-constrained.

Studies that have evaluated the economic benefits of vaccines have found overall large effects. ${ }^{12}$ In particular, a recent analysis found that immunisation programmes could yield substantial financial returns that range from 10 to 25 times that which was invested..$^{13}$ One limitation was, however, the focus on aggregate economic benefits and little discussion on the distributional impact (eg, per socioeconomic group) of vaccines. Current evidence from the literature has shown that morbidity and mortality of vaccine-preventable diseases are disproportionally reduced among the poor when vaccination programmes are implemented. ${ }^{14-16}$ This is mirrored at the international level where vaccine-preventable diseases have a higher impact on low-income and middle-income countries. ${ }^{17}$ The combination of both the within and between country evidence hints that vaccines could have important distributional economic benefits, and that therefore, expanding vaccine coverage could contribute to poverty reduction. ${ }^{12} 18$

As the international community seeks to achieve the SDGs, vaccines may be able to contribute substantially to the post-2015 poverty reduction agenda. This paper develops a cost-epidemiological simulation model to estimate the distributional FRP benefits of three vaccines (measles, rotavirus and pneumococcal conjugate), in low-income and middle-income countries.

\section{METHODS}

In this paper, we develop methods to estimate the effect of three vaccines-measles, rotavirus and pneumococcal conjugate vaccine-on FRP in low-income and middle-income countries. We then illustrate these methods and apply them to the estimation of the number of cases of (1) medical impoverishment and (2) CHCs in 41 countries eligible for funding from Gavi, the Vaccine Alliance (online supplementary appendix table A1) for birth cohorts born over the time period 2016-2030. We restricted our analysis to a subset of the total Gavi-eligible countries for which Demographic and Health Survey (DHS) data were available after 2010 to develop a distributional analysis by socioeconomic group (ie, income quintile). With regard to medical impoverishment, a poverty event is counted when household income minus healthcare costs falls below the World Bank poverty line of $\$ 1.90$ per day-assuming household income was previously above the poverty line. ${ }^{19}$ Alternatively, a case of CHC is counted when OOP healthcare costs are larger than $20 \%$ of household income. These measures of household economic well-being are routinely used by WHO and World Bank to evaluate the financial impact of health policies on households. ${ }^{2320}$

We estimate these two metrics at the monthly level for three immunisation coverage scenarios: (1) no immunisation, (2) the current forecasted immunisation programmes, that is, the current trends of immunisation coverage without any additional funding ('current trends') and (3) the current trends of immunisation coverage enhanced with Gavi funding support for the expansion or implementation of new vaccines ('best case'). These scenarios rely on the model predictions developed by a series of experts, including Gavi, on the long-term volume of vaccines likely to be required among Gavi-eligible countries in the future. ${ }^{21}$ Online supplementary appendix figure A1 presents the average coverage rate of each vaccine for scenarios 2 and 3 in cohorts born between 2000 and 2030. For each scenario, we use a simulation model to obtain aggregate estimates of cases 
of poverty and CHC over 2016-2030 across income quintiles in each country. Per quintile, FRP is calculated as the difference in terms of cases of either poverty or CHC between either scenario (2) or (3) and the base case (1).

\section{Modelling approach}

The FRP model can be described in four steps. First, we obtain the number of incident cases for each disease from disease-specific models (measles, rotavirus and pneumococcal disease) by country. For rotavirus, the cases considered only include severe rotavirus defined by moderate or severe dehydration attributable to rotavirus. ${ }^{22}$ For pneumococcal disease, cases considered included severe pneumococcal pneumonia, meningitis and non-pneumonia/ non-meningitis excluding non-severe pneumonia, otitis media and meningitis sequelae. ${ }^{23}$ Severe pneumococcal pneumonia was defined according to WHO definition of coughing and difficulty breathing. ${ }^{24}$ Further detail on the disease models that provide the disease case inputs for this study is described elsewhere. ${ }^{232526}$ These incident cases are then distributed across income quintiles in each country population. For this, we use a distributional risk approach that varies by specific disease (measles, severe rotavirus or severe pneumococcal disease) developed by Chang et $a l .{ }^{27}$ This approach uses the prevalence and relative risk of a set of risk factors as well as the vaccination coverage gradient to distribute the number of disease cases across income quintiles. Finally, using DHS data, we derive 'healthcare utilisation' likelihoods, that is, the differential probability in healthcare utilisation across income quintiles, to estimate the disease cases treated in each income quintile. Due to the paucity of data on disease incidence within a household, we assumed only one disease case per household.

In step 2, we estimate the total health-related costs incurred by households that can be attributed to each treated disease case. We include OOP direct medical costs: treatment costs for the disease, transportation costs as well as indirect costs for caretaking due to time losses. For this purpose, we use estimates of country treatment provider costs, ${ }^{28-42}$ the average hospitalisation length per disease, the proportion of cases that are hospitalised and transportation costs from/to the health facility. ${ }^{42}$ Additionally, we consider indirect costs defined as the product of hospitalisation or outpatient duration with the hourly wage data for each country. ${ }^{34} 43$ The direct medical costs represent the total cost for the health system; therefore, we use the share of OOP expenditures to total health expenditures ${ }^{2}$ as a proxy for the fraction of the costs that would be borne by individuals. With this data, we estimate total expected (correcting for utilisation) healthcare expenditures for each disease. All costs figures are expressed in \$2011 PPP in order to follow the World Bank standard of poverty measurement. ${ }^{2}$

In the third step, we define the $\mathrm{CHC}$ and poverty cases. For that, we count a CHC case when total health costs exceed $20 \%$ of the monthly household income per capita $^{44}$ and a case of poverty when monthly household income per capita minus health costs becomes lower than the $\$ 1.902011$ PPP per day poverty line. Monthly household income is drawn from a simulated gamma distribution whose shape and scale parameters are based on the country's gross domestic product per capita and Gini coefficient. ${ }^{45} 46$

Finally, we aggregate the number of cases (either CHC or poverty), annually and cumulatively over 2016-2030, for all 41 countries. Thus, per scenario and per disease, we obtain numbers of cases of $\mathrm{CHC}$ and poverty accumulated in this period across income quintiles. All analyses of FRP (CHC and poverty) were pursued using the R Studio V.1.0.143 (www.r-project.org).

\section{Input data}

Table 1 lists all the inputs used in the simulation model, including the average number of annual disease cases in all countries under the three different coverage scenarios over 2016-2030 (no vaccination, current trends and best case), the average patient cost across all countries that an individual would face with each disease and disease incidence and utilisation gradients.

\section{Sensitivity analysis}

First, we conduct two univariate sensitivity analyses. For CHC, we vary the threshold from $10 \%$ to $40 \%$ of household income per capita, instead of $20 \%$ (base case). The second univariate analysis evaluates the role of healthcare utilisation and obtains estimates of $\mathrm{CHC}$ and poverty cases assuming that all individuals in the country have equivalent utilisation to those of the highest income group. Finally, we conduct a probabilistic sensitivity analysis using Monte Carlo simulations ( $\mathrm{n}=1000$ trials), where case distribution, utilisation and costs were varied simultaneously using truncated normal distributions with the inputs' means and $20 \%$ of the means as SD. This allows us to extract the 2.5 and 97.5 percentiles to determine $95 \%$ uncertainty ranges (URs) that are incorporated into our results.

\section{RESULTS}

Figure 1 presents the number of $\mathrm{CHC}$ and medical impoverishment cases attributable to measles for those born from 2016 to 2030 in 41 Gavi-eligible countries by household income quintile. We estimate that approximately 18.9 million households (95\% UR 16.4-21.4) would have CHC attributable to measles in the absence of any vaccination coverage. This represents approximately $35 \%$ of the birth cohort born in these countries in 2016 assuming one susceptible child per household. The number of CHC decreases to 3.4 million households (2.9-3.4) that is approximately $5 \%$ of the 2016 birth cohort in these countries if the current coverage forecasts remain and to 2.6 million (2.2-3.0) if coverage was enhanced with Gavi support. For medical impoverishment, the number of households that would fall under the poverty line due to medical expenditures attributable to measles would be 5.3 million (4.8-5.3) in the absence of any vaccination 
Table 1 Inputs used in the simulation model estimating cases of poverty and catastrophic health costs due to measles, severe rotavirus and severe pneumococcal disease, in 41 low-income and middle-income countries

Average (min-max)

across countries

Reference

(a) Total number of cases (2016-2030) in 1000s

Scenario 1: no vaccination

\begin{tabular}{lcc} 
Measles & $16709(378-107443)$ & 212526 \\
$\begin{array}{l}\text { Severe pneumococcal } \\
\text { disease }\end{array}$ & $675(6-4648)$ & 212325 \\
Severe rotavirus & $1555(28-10573)$ & 212325 \\
\hline
\end{tabular}

Scenario 2: current

coverage trends

\begin{tabular}{|c|c|c|}
\hline Measles & $2196(8-34$ 182) & 212526 \\
\hline $\begin{array}{l}\text { Severe pneumococcal } \\
\text { disease }\end{array}$ & $658(5-4256)$ & 212325 \\
\hline Severe rotavirus & $1485(13-10573)$ & 212325 \\
\hline \multicolumn{3}{|l|}{ Scenario 3: best case } \\
\hline Measles & $1279(6-14530)$ & 212526 \\
\hline $\begin{array}{l}\text { Severe pneumococcal } \\
\text { disease }\end{array}$ & $467(4-3383)$ & 212325 \\
\hline Severe rotavirus & $948(4-7890)$ & 212325 \\
\hline
\end{tabular}

(b) Provider treatment costs

\begin{tabular}{|c|c|c|}
\hline \multicolumn{3}{|l|}{ Inpatient costs } \\
\hline Measles & $\$ 12.0(1.4-53.5)$ & $23038-41$ \\
\hline $\begin{array}{l}\text { Severe pneumococcal } \\
\text { disease }\end{array}$ & $\$ 51.2(6.2-241.3)$ & $\begin{array}{l}228-3437 \\
39-41\end{array}$ \\
\hline Severe rotavirus & $\$ 38.0(4.4-171.0)$ & $\begin{array}{l}2303536 \\
39-41\end{array}$ \\
\hline \multicolumn{3}{|l|}{ Outpatient hospital costs } \\
\hline Measles & $\$ 2.8(0.6-9.1)$ & $23038-41$ \\
\hline $\begin{array}{l}\text { Severe pneumococcal } \\
\text { disease }\end{array}$ & $\$ 2.7(0.6-9.1)$ & $\begin{array}{l}228-3437 \\
39-41\end{array}$ \\
\hline Severe rotavirus & $\$ 2.7(0.6-9.1)$ & $\begin{array}{l}2303536 \\
39-41\end{array}$ \\
\hline
\end{tabular}

\begin{tabular}{lll}
$\begin{array}{l}\text { Outpatient health centre } \\
\text { costs }\end{array}$ & & \\
\hline $\begin{array}{l}\text { Measles } \\
\text { Severe pneumococcal } \\
\text { disease }\end{array}$ & $\$ 1.4(0.3-4.5)$ & $23038-41$ \\
\hline Severe rotavirus & $\$ 1.3(0.3-4.5)$ & $\begin{array}{l}228-3437 \\
39-41\end{array}$ \\
\hline $\begin{array}{l}\text { Transport costs } \\
\text { Measles }\end{array}$ & $39-4136$ \\
\hline $\begin{array}{l}\text { Severe pneumococcal } \\
\text { disease }\end{array}$ & $\$ 2.0(0.2-9.4)$ & 34 \\
\hline $\begin{array}{l}\text { Severe rotavirus } \\
\text { (c) Health gradients }\end{array}$ & $\$ 2.1(0.2-9.4)$ & 34 \\
\hline Disease case distribution & & \\
\hline 1st quintile (poorest) & $22 \%(6-31)$ & 27 \\
\hline 2nd quintile & $22 \%(13-25)$ & 27 \\
\hline 3rd quintile & $20 \%(15-24)$ & 27 \\
\hline 4th quintile & $20 \%(14-30)$ & 27 \\
\hline
\end{tabular}

Continued
Table 1 Continued

\begin{tabular}{lcl}
\hline & $\begin{array}{c}\text { Average (min-max) } \\
\text { across countries }\end{array}$ & Reference \\
\hline $\begin{array}{l}\text { 5th quintile (highest) } \\
\text { Healthcare access } \\
\text { likelihood }\end{array}$ & $16 \%(11-28)$ & 27 \\
1st quintile (poorest) & $43 \%(11-76)$ & 41 \\
\hline 2nd quintile & $45 \%(24-76)$ & 41 \\
3rd quintile & $49 \%(25-78)$ & 41 \\
4th quintile & $50 \%(25-75)$ & 41 \\
5th quintile (highest) & $56 \%(33-78)$ & 41 \\
\hline
\end{tabular}

Note. Table presents the average value as well as a minimum and maximum in parentheses for the set of countries studied. Current coverage trends represent current vaccination forecasts. Best case includes additional Gavi funding for the expansion or implementation of vaccines.

coverage, 0.7 million $(0.6-0.8)$ under the current trends of immunisation coverage and 0.5 million $(0.4-0.6)$ if Gavi support was provided. Overall, the results show that vaccine coverage can reduce by approximately $90 \%$ the incidence of $\mathrm{CHC}$ attributable to measles.

Figures 2 presents similar estimates attributable to severe pneumococcal disease. We find that approximately 6.6 (6.3-6.9) million households would suffer from CHC between 2016 and 2030 in the absence of vaccine coverage. In contrast to measles, under the current prevailing conditions of vaccine coverage, the number of CHC cases would only decrease slightly to 6.4 million (6.1-6.7) and is explained by the common absence of the pneumococcal conjugate vaccine in current country vaccination programmes. This represents approximately $13 \%$ of the 2016 birth cohorts of these countries. This vaccine will be implemented or expanded with Gavi support in some countries, and under this scenario, the number of households with CHC cases would decrease to 4.6 million (4.4-4.8) representing a decrease of approximately $30 \%$. A similar conclusion is drawn from the medical impoverishment estimates where without vaccine coverage, 0.8 million (0.7-0.9) households would fall under the poverty line. This value is similar under the current forecasts, but with Gavi support, the number of households that fall under the poverty line due to healthcare expenditures would decrease to 0.6 million $(0.5-0.6)$.

Figure 3 presents the estimated number of $\mathrm{CHC}$ and medical impoverishment cases attributable to severe rotavirus by household income quintile. The numbers are considerably lower than in the cases of measles and severe pneumococcal disease. Without any vaccine coverage, we estimate 2.2million $\mathrm{CHC}$ cases (2.1-2.4) and 0.6 (0.6-0.7) million medical impoverishment cases. These numbers would not significantly decrease under the current forecasts: to 2.1 million (2.0-2.4) and 0.6 million $(0.6-0.7)$, respectively. This is because very few countries have introduced the rotavirus vaccine. Nevertheless, the implementation and expansion of the rotavirus vaccine 

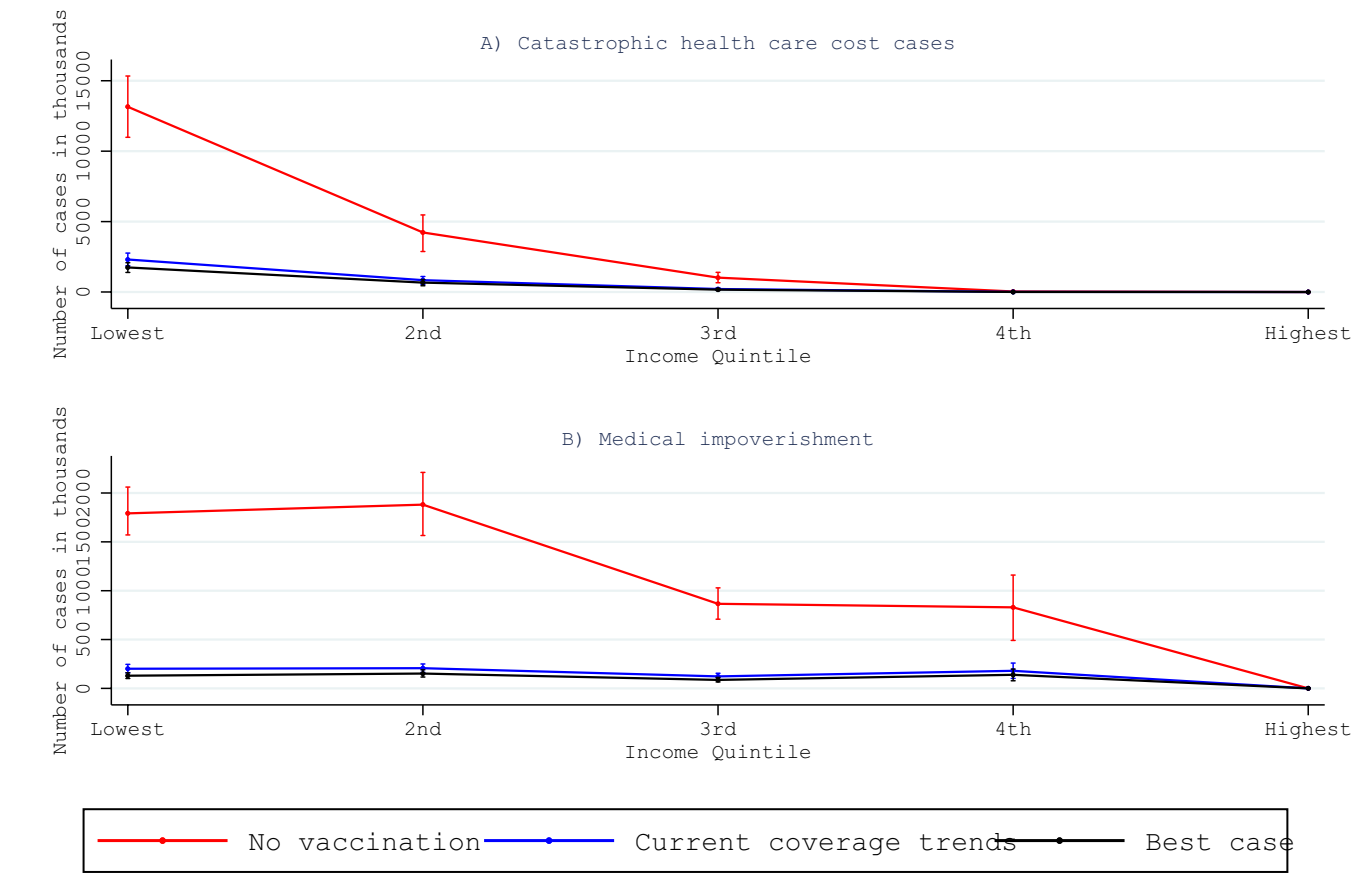

Note: Figures present the average value of cases by economic quintile with 95\% uncertainty ranges. Current coverage trends represent current vaccination forecasts.

Best case includes additional Gavi funding for the expansion or implementation of vaccines.

Figure 1 Household cases of catastrophic health costs and medical impoverishment attributable to measles in 41 low-income and middle-income countries for the cohorts born between 2016 and 2030.

in the best-case scenario would reduce the number of CHC cases to 1.3 million (1.2-1.5) and medical impoverishment cases to $0.4(0.3-0.4)$. As in the case of severe pneumococcal disease, this represents an approximate $40 \%$ reduction from the no vaccination or current forecasts scenario.
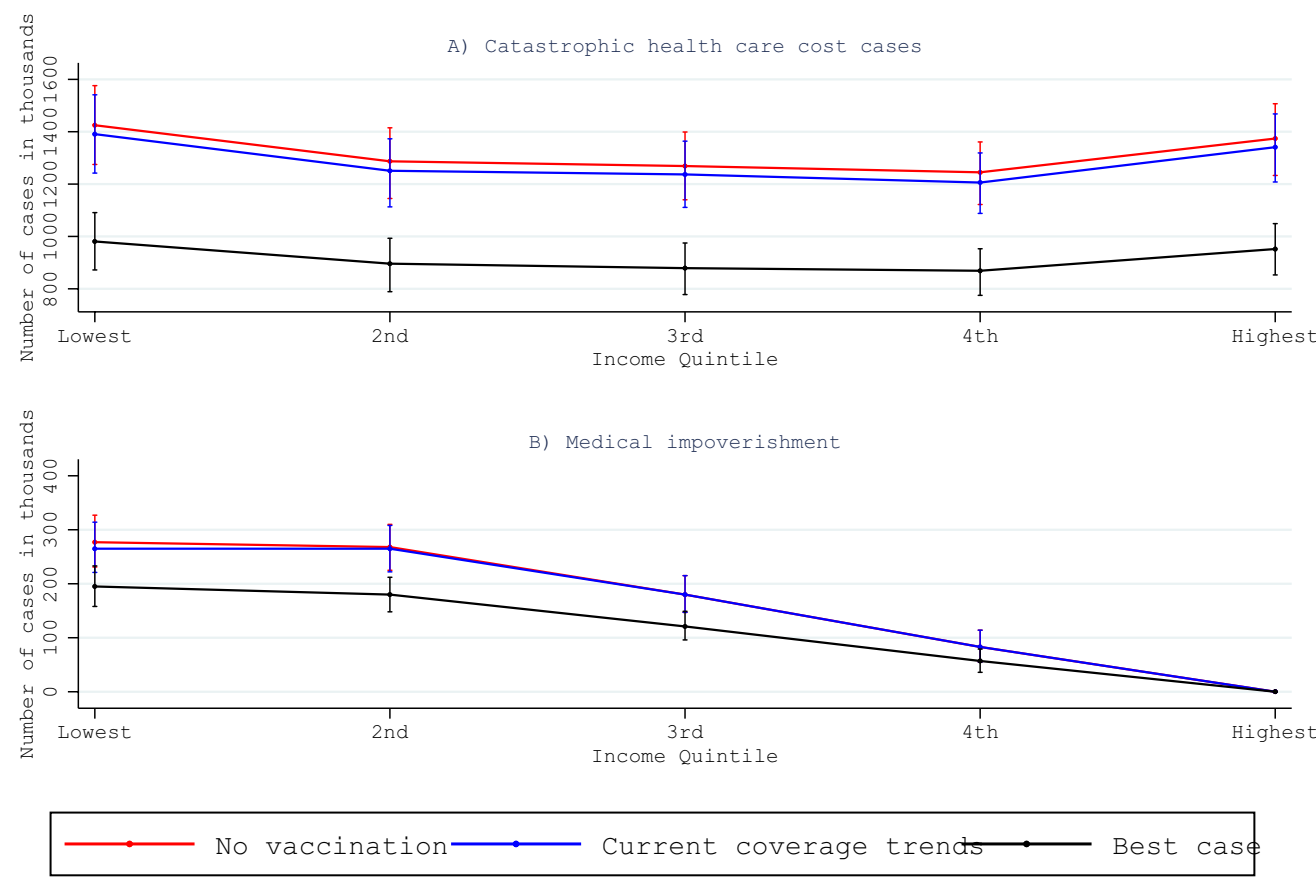

Note: Figures present the average value of cases by economic quintile with $95 \%$ uncertainty ranges.

Best case includes additional Gavi funding for the expansion or implementation of vaccines.

Figure 2 Household cases of catastrophic health costs and medical impoverishment attributable to severe pneumococcal pneumonia in 41 low-income and middle-income countries for the cohorts born between 2016 and 2030. 

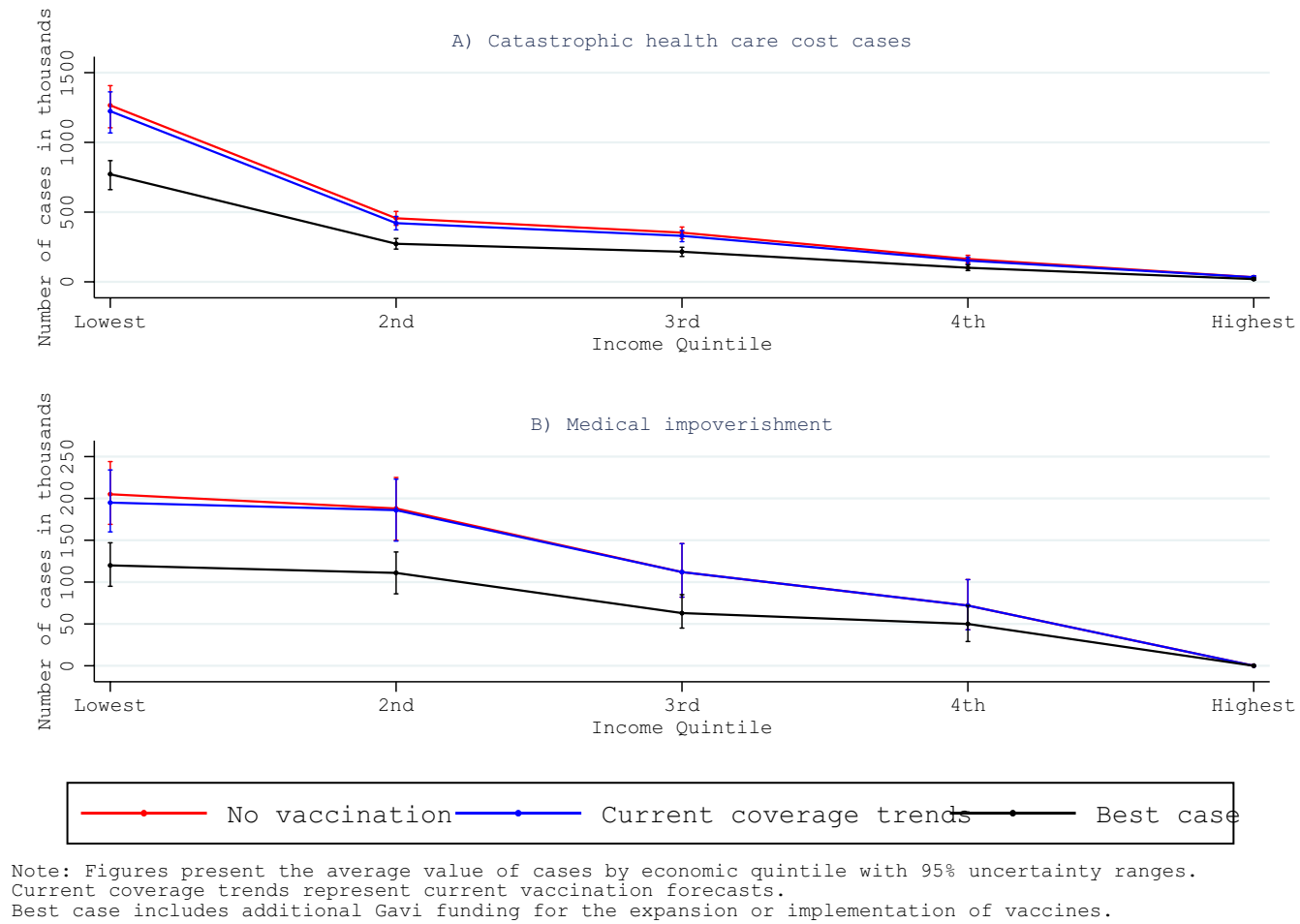

Figure 3 Household cases of catastrophic health costs and medical impoverishment attributable to severe rotavirus in 41 low-income and middle-income countries for the cohorts born between 2016 and 2030.

In the case of measles and severe rotavirus, the figures above also show that the share of CHC and medical impoverishment cases is larger in households from the lower-income quintiles. From the estimates above, we calculate the number of CHC cases averted under the current prevailing conditions with and without Gavi support (table 2) and estimate the share of averted cases in each quintile. Table 2 shows that of the approximately 12.5 million cases of $\mathrm{CHC}$ attributable to measles that will be averted under current coverage trends, $75 \%$ (95\% UR 70-81) of them will occur in the households from the lowest income quintile. The value for severe rotavirus is lower, $40 \%(30-51)$, but is nevertheless the largest across income quintiles. This gradient is even smaller for severe pneumococcal disease. However, enhancing the coverage of vaccines to the best-case scenario would not only lead to a larger number of CHC cases averted but also increase the share of protected households in the lowest quintile. For example, with increased Gavi funding, 57\% (53-61) of all the averted CHC cases attributable to severe rotavirus would occur in the lowest income quintile. These results highlight that not only can vaccines decrease considerably the number of CHC cases but they also have the potential of disproportionately improving the financial conditions of the poor. The estimates for medical impoverishment lead to similar conclusions with the share of averted cases decreasing with income quintile and emphasising the pro-poor financial benefits of vaccines (online supplementary appendix tables A2 and 3).
Figures 4-6 also show the total OOP expenditures attributable to measles, severe pneumococcal disease and severe rotavirus by income quintile for birth cohorts from 2016 to 2030. In contrast to the results for FRP, expenditures are larger in the highest income quintiles in line with their higher healthcare utilisation. These estimates, however, show that expanding the coverage of vaccines leads to an important reduction in total OOP expenditures. Under the current vaccine coverage forecasts, the amount of OOP expenditures averted would be 4.3 billion (4.1-4.7) 2011 International \$ PPP for measles, $\$ 36$ million (30-43) for severe pneumococcal disease and $\$ 70$ million (58-82) for severe rotavirus (online supplementary appendix table A4). The averted expenditures further increase to \$4.6billion (4.2-5.0) for measles, \$168 million (156-181) for severe pneumococcal disease and \$200million for severe rotavirus (184-215) when including Gavi support (online supplementary appendix table A4). In line with the figures, the larger share of the total OOP health expenditures averted would occur in the higher-income quintiles as shown in online supplementary appendix table A5.

\section{Sensitivity analysis}

Online supplementary appendix tables A2 to 10 present the univariate sensitivity analyses testing for the effects of the CHC threshold, the assumptions underlying the fraction of healthcare utilisation and the distribution of vaccine coverage with and without total fertility rate (TFR) adjustments. In the case of the thresholds (online 
Table 2 Percentage and number in 1000s of total catastrophic health costs cases averted by vaccines in 41 low-income and middle-income countries for those born between 2016 and 2030

\begin{tabular}{|c|c|c|c|}
\hline & (1) & (2) & (3) \\
\hline & $\begin{array}{l}\text { Measles vaccine } \\
(95 \% \text { UR) }\end{array}$ & $\begin{array}{l}\text { Pneumococcal conjugate } \\
\text { vaccine }(95 \% \text { UR) }\end{array}$ & $\begin{array}{l}\text { Rotavirus vaccine } \\
\text { (95\% UR) }\end{array}$ \\
\hline Current covera & & & \\
\hline Lowest & $75.2 \%(69.6-80.8)$ & $22.2 \%(15.8-28.8)$ & $40.4 \%(29.6-51.1)$ \\
\hline & $12506(10636-14$ 409) & $38(26-51)$ & $47(31-64)$ \\
\hline 2nd quintile & $19.9 \%(14.3-25.4)$ & $21.7 \%(15.2-28.7)$ & $30.3 \%(19.7-40.7)$ \\
\hline & $3286(2290-4268)$ & $37(24-50)$ & $36(21-49)$ \\
\hline 3rd quintile & $4.7 \%(3.1-6.5)$ & $18.4 \%(12.6-25.3)$ & $19.6 \%(11.3-27.8)$ \\
\hline & 779 (501-1045) & $32(20-44)$ & $22(12-34)$ \\
\hline 4th quintile & $0.1 \%(0.1-0.2)$ & $20.2 \%(14.0-26.3)$ & $9.4 \%(3.9-15.5)$ \\
\hline & 19 (10-29) & $34(23-46)$ & $11(4-18)$ \\
\hline Highest & $0.0 \%(0.0-0.0)$ & $17.4 \%(11.6-23.1)$ & $0.0 \%(0.0-1.6)$ \\
\hline & $0(0-1)$ & $30(18-40)$ & $0(0-2)$ \\
\hline Best case & & & \\
\hline Lowest & $75.2 \%(69.7-80.8)$ & $24.7 \%$ (22.1-27.2) & $57.4 \%(53.1-61.3)$ \\
\hline & $13097(11110-15$ 108) & $495(438-558)$ & $536(469-604)$ \\
\hline 2nd quintile & $19.9 \%(14.2-25.3)$ & $20.7 \%(18.5-22.9)$ & $20.4 \%(17.6-23.4)$ \\
\hline & 3442 (2384-4472) & 416 (366-465) & $190(161-220)$ \\
\hline 3rd quintile & $4.8 \%(3.1-6.6)$ & $19.6 \%(17.3-21.7)$ & $14.8 \%(12.3-17.5)$ \\
\hline & $826(532-1106)$ & $394(346-442)$ & $138(114-162)$ \\
\hline 4th quintile & $0.1 \%(0.1-0.2)$ & $17.7 \%(15.7-19.6)$ & $6.2 \%(4.7-7.8)$ \\
\hline & $20(11-30)$ & 354 (312-394) & $57(44-72)$ \\
\hline Highest & $0.0 \%(0.0-0.0)$ & $17.5 \%(15.5-19.3)$ & $1.2 \%(0.6-1.9)$ \\
\hline & $0(0-1)$ & $351(309-391)$ & $10(6-17)$ \\
\hline
\end{tabular}

Note. Current coverage trends represent current vaccination forecasts. Best case includes additional Gavi funding for the expansion or implementation of vaccines. Figures present the average value of cases by economic quintile with $95 \%$ URs. $95 \%$ URs are given in parentheses.

UR, uncertainty range.

supplementary appendix figures A2,3 and 4), we find that, as expected, increasing the threshold leads to a lower number of cases. However, the results still show large number of $\mathrm{CHC}$ cases and most importantly in the bottom income quintiles. One important aspect to note is that if we used a threshold of $10 \%$, the total number of CHC cases in the absence of immunisation would be 49 million, 7 million and 5 million for measles, severe pneumococcal disease and severe rotavirus, respectively. This would represent approximately 100\%, 15\% and $10 \%$ of the 2016 birth cohort of these 41 countries. Under the best-case scenario, the number of cases using the $10 \%$ threshold would decrease to 6 million, 3 million and 3 million, respectively, emphasising the importance of vaccines even when considering different thresholds. Online supplementary appendix figures A5 to 7 present the results assuming that all income quintiles achieve the highest utilisation observed in the country. As expected, the number of $\mathrm{CHC}$ and poverty cases increases since individuals are more likely to use healthcare if ill while facing similar OOP costs. The effects are substantial and show an increase under the $20 \%$ threshold to approximately 23 million cases for measles, 8 million cases for severe pneumococcal disease and 3 million for severe rotavirus. As before, under the best-case scenario, the numbers decrease to 3 million, 6 million and 2 million, respectively. The similarity of the conclusions emphasises the importance of vaccines and their role in protecting households financially from OOP health expenditures. Finally, online supplementary appendix figures A8 to 10 show that TFR adjustments across quintiles do not lead to important differences in the results.

\section{DISCUSSION}

This paper develops a methodology to estimate how cases of $\mathrm{CHC}$ and medical impoverishment incurred by vaccine-preventable diseases would be distributed across socioeconomic status and to quantify the likely FRP benefits of immunisation programmes. We find that 


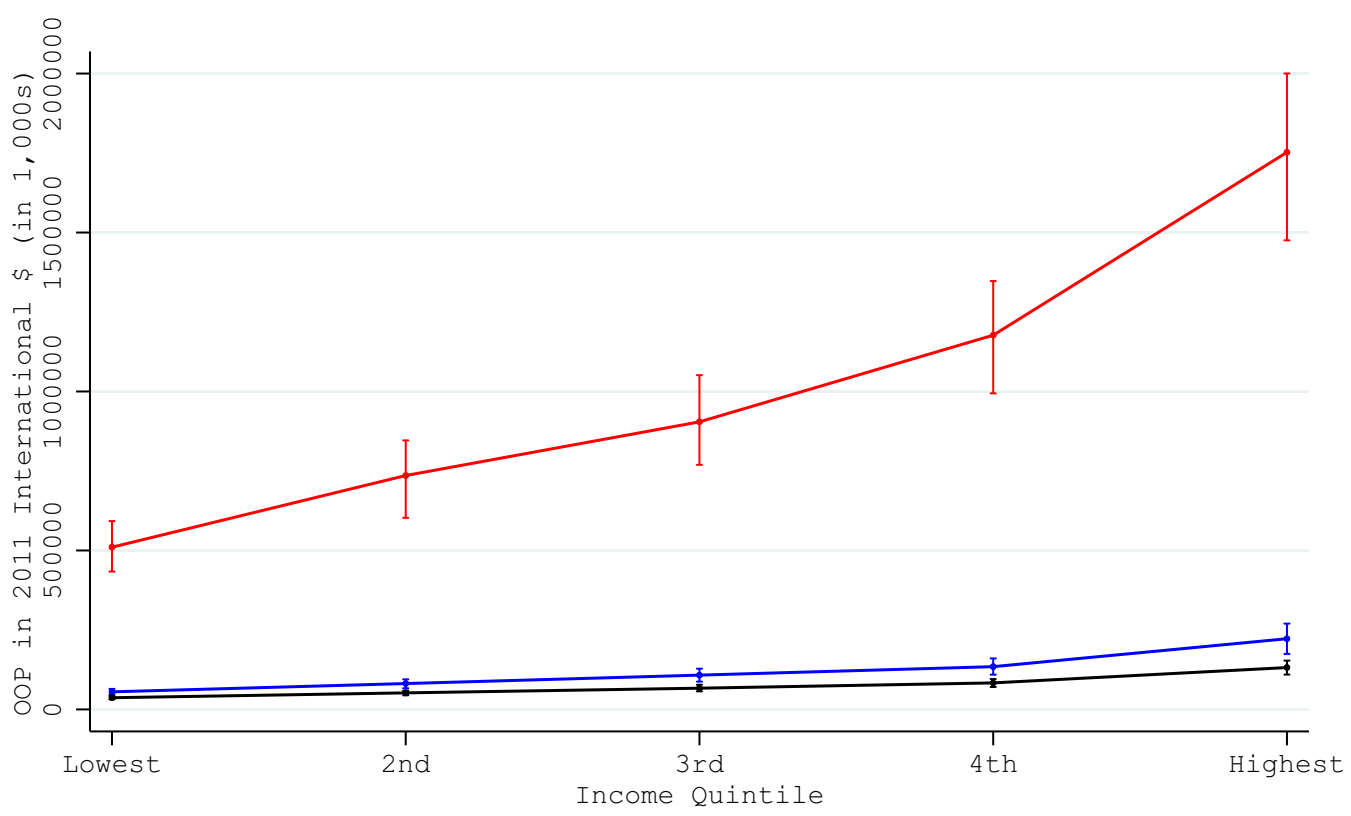

$$
\longrightarrow \text { No vaccination } \longrightarrow \text { Current coverage trencts } \longrightarrow \text { Best cas }
$$

Note: Figures present the average value of cases by economic quintile with $95 \%$ uncertainty ranges. Current coverage trends represent current vaccination forecasts.

Best case includes additional Gavi funding for the

Figure 4 Total OOP health expenditures attributable to measles in 41 low-income and middle-income countries for the cohorts born between 2016 and 2030. OOP, out-of-pocket.

in the absence of immunisation, there would be about 19 million CHC cases attributable to measles, 7 million to severe pneumococcal disease and 2 million to severe rotavirus for cohorts born between 2016 and 2030 in 41 low-income and middle-income countries. Conversely, if projected coverage increases to the best-case scenario,

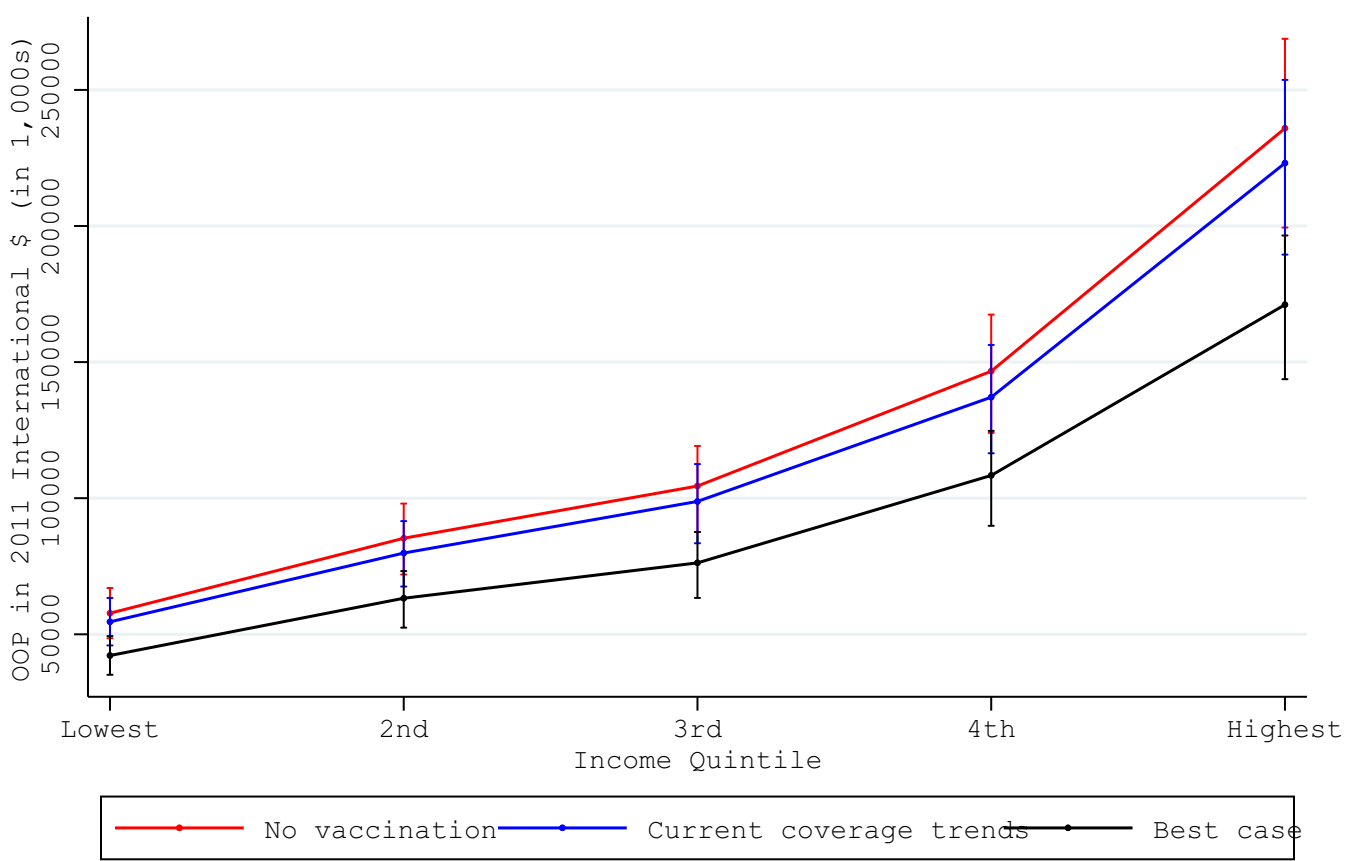

Note: Figures present the average value of cases by economic quintile with $95 \%$ uncertainty ranges. Current coverage trends represent current vaccination forecasts.

Best case includes additional Gavi funding for the expansion or implementation of vaccines.

Figure 5 Total OOP health expenditures attributable to severe pneumococcal disease in 41 low-income and middle-income countries for the cohorts born between 2016 and 2030. OOP, out-of-pocket. 


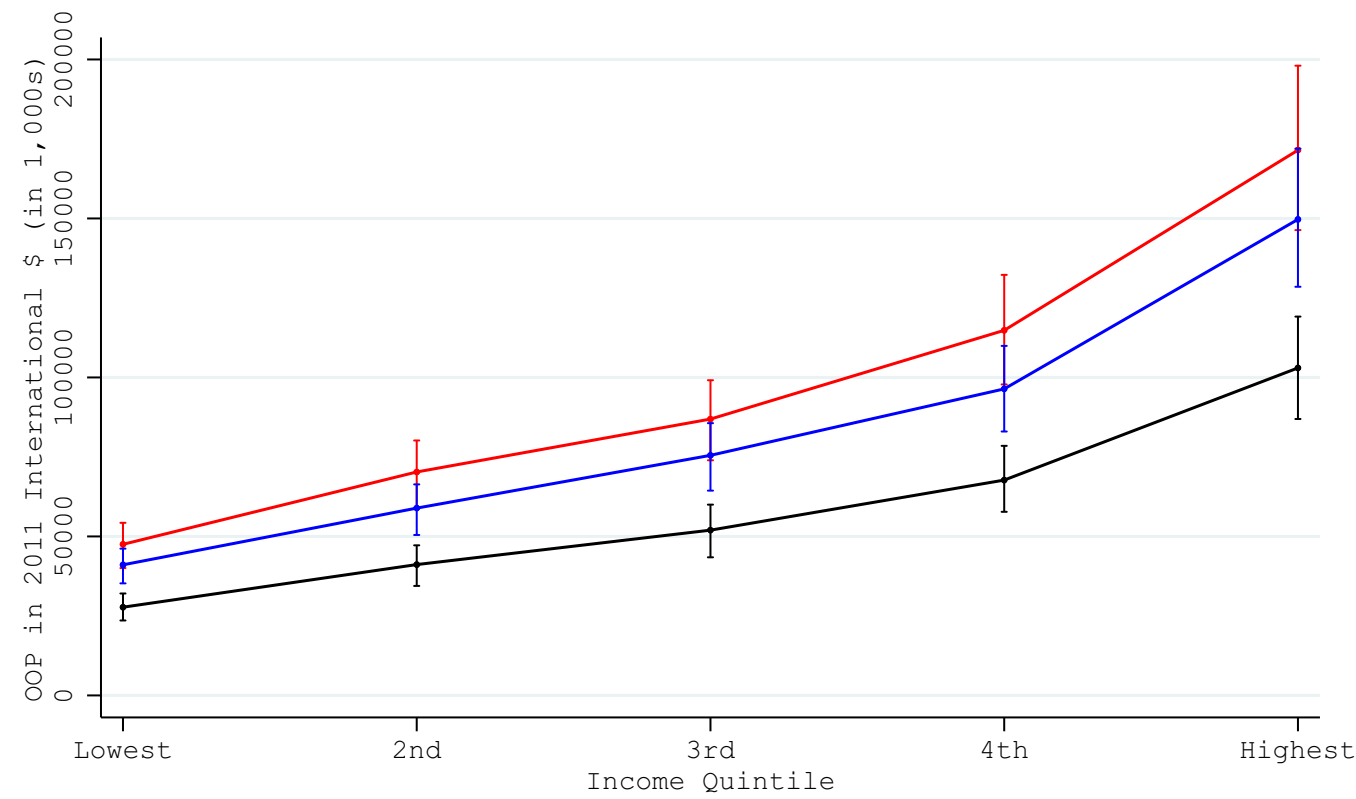

Figure 6 Total OOP health expenditures attributable to severe rotavirus in 41 low-income and middle-income countries for the cohorts born between 2016 and 2030. OOP, out-of-pocket.

that is, including Gavi funding for the expansion and implementation of new vaccines, the incidence of $\mathrm{CHC}$ could decrease to 3 million, 5 million and 1 million, respectively. Similar estimates are obtained when considering other indicators of FRP such as cases of medical impoverishment. These results emphasise the fundamental role that vaccines can have in the global agenda to protect households' financial well-being as well as reduce the incidence of medical impoverishment.

Furthermore, not only the burden of $\mathrm{CHC}$ and medical impoverishment would be greater in the lowest income quintiles but also the expanding vaccine coverage could provide larger FRP to the poorest quintiles. An important protective gradient could incur where the share of averted cases in relation to the total number of cases averted would be larger in the lowest income quintiles. Consequently, vaccines not only could enhance financial protection from OOP health expenditures but also could benefit more those that are worst off.

Finally, we estimate that under the best-case scenario, current coverage trends with enhanced Gavi funding, the amount of OOP health expenditures averted would surpass $\$ 4.5$ billion (2011 International \$) attributable to measles, $\$ 168$ million attributable to severe pneumococcal disease and \$200million attributable to severe rotavirus. Therefore, expanding vaccine coverage would improve household financial well-being by increasing disposable income that could further improve their living conditions.
Overall, this paper provides additional information for decision makers to consider when setting national priorities and can help place poverty reduction as a major outcome of health interventions with the objective of achieving the SDGs by 2030. In particular, this methodology helps incorporating poverty reduction and FRP as a criterion to design a basic health benefits package including publicly financed immunisations, where both FRP and cost-effectiveness are taken into account, consistent with extended cost-effectiveness analysis methods ${ }^{47-49}$ and frameworks of multicriteria decision analysis. ${ }^{50}$ Our approach also quantifies cost-effective health-policy investments in terms of poverty reduction that can be included in discussions outside of the health sector such as agriculture or education and for ministries of finance and development. ${ }^{51}$

Our analysis presents, nevertheless, several limitations. First, data on OOP expenditures and impoverishment are lacking substantially, and therefore, we had to rely on information available for a small set of countries and imputed data. ${ }^{52-55}$ Additionally, there is paucity of information on treatment costs and OOP costs that emphasise the need of further studies in this area. Our CHC and poverty cases estimates rely on disease case outputs from disease and forecast models that have their own limitations. ${ }^{21} 252642$ Furthermore, one may need to repeat these analyses as forecasts evolve to estimate the future financial protection benefits of vaccines. As a consequence, our results are related to the assumptions in these models 
such as the type of vaccines considered. Nevertheless, we pursued sensitivity analyses, and our results were robust to different sets of parameter assumptions that could have more importance on medical impoverishment and CHCs. Second, there are modelling assumptions from our financial protection simulation model itself with regard to the distributions of income and costs in the different populations. Some of our results, therefore, need to be interpreted with caution and also call for better data collection in the domain of OOP healthcare costs, access to healthcare and on risk factors to understand the distribution of cases across income quintiles. Furthermore, we presented a relatively simple FRP model, but one could develop more complexity that includes discounting and income growth over time (currently not incorporated in our model), as well as other social benefits or costs, for example. Another limitation is that we have chosen specific measures of FRP that rely on income-based thresholds to quantify the number of cases of $\mathrm{CHC}$ and poverty. ${ }^{44}$ This simplification also implies that the counterfactual excludes the possibility that these households would fall below the poverty line for other reasons during the same month. A final limitation of this analysis is the paucity of data concerning incidence of disease within a household.

Overall, our paper suggests that immunisation not only would have an important effect on economic well-being of a country but also would prevent disease-related hospitalisation, associated impoverishment and could provide significant financial protection to households, particularly the poorest who are at higher risks, have reduced access to healthcare and bear significant economic costs due to disease treatment. As the world aims to eliminate poverty by 2030 , immunisation could play a key role in setting policy for the poverty reduction agenda.

\section{Author affiliations \\ 'Department of Global Health and Population, Harvard TH Chan School of Public Health, Boston, Massachusetts, USA \\ ${ }^{2}$ Department of Applied Economics, Erasmus School of Economics, Erasmus University of Rotterdam, Rotterdam, The Netherlands \\ ${ }^{3}$ Pharmaceutical Outcomes Research and Policy Program, University of Washington, Seattle, Washington, USA \\ ${ }^{4}$ Department of International Health, Johns Hopkins Bloomberg School of Public Health, Baltimore, Maryland, USA \\ ${ }^{5}$ Department of Health Services Research and Policy, London School of Hygiene and Tropical Medicine, London, UK \\ ${ }^{6}$ Bill and Melinda Gates Foundation, Washington DC, USA}

Contributors $\mathrm{CR}-\mathrm{H}$ and SV developed the modelling methods and analysed the data. CR-H ran the analyses and wrote the first draft of the manuscript. SV reviewed the paper. AYC, SC, DC and AC developed the data inputs and reviewed the paper. LB provided advice and suggestions and reviewed the paper.

Funding This work was supported by the Bill and Melinda Gates Foundation (00P1137904). This paper was presented at a BMGF-Gavi Impact Modelling Meeting in Evian, France in 2016, and we received useful comments from meeting participants.

Competing interests None declared.

Patient consent Not required.

Provenance and peer review Not commissioned; externally peer reviewed.
Open Access This is an Open Access article distributed in accordance with the terms of the Creative Commons Attribution (CC BY 4.0) license, which permits others to distribute, remix, adapt and build upon this work, for commercial use, provided the original work is properly cited. See: http://creativecommons.org/ licenses/by/4.0/

(C) Article author(s) (or their employer(s) unless otherwise stated in the text of the article) 2018. All rights reserved. No commercial use is permitted unless otherwise expressly granted.

\section{REFERENCES}

1. United Nations. Sustainable Development Goals. 2015.

2. World Bank World Development Indicators. Washington, DC, 2017. https://openknowledge.worldbank.org/

3. Xu K, Evans DB, Carrin G, et al. Protecting households from catastrophic health spending. Health Aff 2007;26:972-83.

4. Falkingham J, Poverty FJ. Poverty, out-of-pocket payments and access to health care: evidence from Tajikistan. Soc Sci Med 2004;58:247-58.

5. Flores G, Krishnakumar J, O'Donnell O, et al. Coping with healthcare costs: implications for the measurement of catastrophic expenditures and poverty. Health Econ 2008;17:1393-412.

6. van Doorslaer E, O'Donnell O, Rannan-Eliya RP, et al. Effect of payments for health care on poverty estimates in 11 countries in Asia: an analysis of household survey data. Lancet 2006;368:1357-64

7. Evans DB, Hsu J, Boerma T. Universal health coverage and universal access. Bull World Health Organ 2013;91:546-546A.

8. Saksena P, Hsu J, Evans DB. Financial risk protection and universal health coverage: evidence and measurement challenges. PLoS Med 2014;11:e1001701.

9. Wagstaff A, Cotlear D, Eozenou $\mathrm{PH}-\mathrm{V}$, et al. Measuring progress towards universal health coverage: with an application to 24 developing countries. Oxford Review of Economic Policy 2016;32:147-89.

10. Xu K, Evans DB, Kawabata K, et al. Household catastrophic health expenditure: a multicountry analysis. Lancet 2003;362:111-7.

11. World Health Organization. Global Vaccine Action Plan: 2011-2020, 2011. http://www.who.int/immunization/global_vaccine_action_plan/ GVAP_doc_2011_2020/en/.

12. Bloom DE, Canning D, Weston M. The value of vaccination. World Economics 2005;6:15.

13. Ozawa S, Clark S, Portnoy A, et al. Return on investment from childhood immunization in low- and middle-income countries, 201120. Health Aff 2016;35:199-207.

14. Hosseinpoor AR, Bergen N, Schlotheuber A, et al. Data Resource Profile: WHO Health Equity Monitor (HEM). Int $J$ Epidemiol 2016:45:1404-5.

15. Lob-Levyt J. Vaccines for the poor. Bulletin of the World Health Organization 2008;86:427-8.

16. Wagstaff A, Bredenkamp C, Buisman LR. Progress on global health goals: are the poor being left behind? World Bank Res Obs 2014;29:137-62.

17. Vos T, Allen C, Arora M, et al. Global, regional, and national incidence, prevalence, and years lived with disability for 310 diseases and injuries, 1990-2015: a systematic analysis for the Global Burden of Disease Study 2015. Lancet 2016;388:1545-602.

18. MacLennan CA, Saul A. Vaccines against poverty. Proc Natl Acad Sci U S A 2014:111:12307-12.

19. Ferreira FHG, Chen S, Dabalen A, et al. A global count of the extreme poor in 2012: data issues, methodology and initial results. The Journal of Economic Inequality 2016;14:141-72.

20. World Health Organization. Tracking universal health coverage: first global monitoring report: World Health Organization, 2015.

21. Gavi. Strategic Demand Forecast Version 12.0. 2016 http://www. gavi.org/about/market-shaping/strategic-demand-scenarios/.

22. Walker CLF, Rudan I, Liu L, et al. Global burden of childhood pneumonia and diarrhoea. The Lancet 2013;381:1405-16.

23. Clark A, Jauregui B, Griffiths U, et al. TRIVAC decision-support model for evaluating the cost-effectiveness of Haemophilus influenzae type $b$, pneumococcal and rotavirus vaccination. Vaccine 2013;31:C19-C29.

24. Rudan I, Boschi-Pinto C, Biloglav Z, et al. Epidemiology and etiology of childhood pneumonia. Bull World Health Organ 2008;86:408-16.

25. Lee LA, Franzel L, Atwell J, et al. The estimated mortality impact of vaccinations forecast to be administered during 20112020 in 73 countries supported by the GAVI Alliance. Vaccine 2013;31:B61-B72. 
26. Simons E, Ferrari M, Fricks J, et al. Assessment of the 2010 global measles mortality reduction goal: results from a model of surveillance data. Lancet 2012;379:2173-8.

27. Chang A, Riumallo-Herl C, Salomon J, et al. Estimating the distribution of morbidity and mortality of childhood diarrhea, measles, and pneumonia by wealth group in low- and middleincome countries. BMC Medicine. Under Review.

28. Akumu AO, English M, Scott JA, et al. Economic evaluation of delivering Haemophilus influenzae type $b$ vaccine in routine immunization services in Kenya. Bull World Health Organ 2007;85:511-8.

29. Broughton El. Economic evaluation of Haemophilus influenzae type $B$ vaccination in Indonesia: a cost-effectiveness analysis. J Public Health 2007;29:441-8.

30. WHO Choice. Country-specific unit costs, 2012. http://www.who.int/ choice/en/.

31. Gessner BD, Sedyaningsih ER, Griffiths UK, et al. Vaccinepreventable haemophilus influenza type $B$ disease burden and costeffectiveness of infant vaccination in Indonesia. Pediatr Infect Dis $J$ 2008;27:438-43.

32. Giglio ND, Cane AD, Micone P, et al. Cost-effectiveness of the CRM-based 7-valent pneumococcal conjugated vaccine (PCV7) in Argentina. Vaccine 2010;28:2302-10.

33. Hussain $\mathrm{H}$, Waters $\mathrm{H}$, Khan AJ, et al. Economic analysis of childhood pneumonia in Northern Pakistan. Health Policy Plan 2008;23:438-42.

34. Kim SY, Sweet S, Slichter D, et al. Health and economic impact of rotavirus vaccination in GAVI-eligible countries. BMC Public Health 2010;10:253.

35. Parashar UD, Hummelman EG, Bresee JS, et al. Global illness and deaths caused by rotavirus disease in children. Emerg Infect Dis 2003;9:565-72.

36. Rheingans RD, Antil L, Dreibelbis R, et al. Economic costs of rotavirus gastroenteritis and cost-effectiveness of vaccination in developing countries. J Infect Dis 2009;200:S16-S27.

37. Sinha A, Levine O, Knoll MD, et al. Cost-effectiveness of pneumococcal conjugate vaccination in the prevention of child mortality: an international economic analysis. Lancet 2007;369:389-96

38. Thompson KM, Odahowski CL. The costs and valuation of health impacts of measles and rubella risk management policies. Risk Anal 2016;36:1357-82.

39. UNICEF. Multiple indicator cluster survey (MICS), 2000. http://mics. unicef.org/.

40. UNICEF. The State of the World's Children 2012: Children in an Urban World: United Nations Publications, 2012.
41. USAID. Demographic and Health Surveys (DHS) Program, 2016. https://dhsprogram.com/.

42. Ozawa S, Clark S, Portnoy A, et al. Estimated economic impact of vaccinations in 73 low- and middle-income countries, 2001-2020. Bull World Health Organ 2017;95:629-38.

43. Laborstat. Database on labour statistics, 2016. http://www.ilo.org/ ilostat/.

44 Wagstaff A, van Doorslaer E. Catastrophe and impoverishment in paying for health care: with applications to Vietnam 1993-1998. Health Econ 2003;12:921-33.

45. Kemp-Benedict E. Income distribution and poverty: methods for using available data in global analysis. PoleStar Technical Notes, 2001.

46. Salem ABZ, Mount TD. A convenient descriptive model of income distribution: the gamma density. Econometrica 1974;42:1115-27.

47. Verguet S, Laxminarayan R, Jamison DT. Universal public finance of tuberculosis treatment in India: an extended cost-effectiveness analysis. Health Econ 2015;24:318-32.

48. Verguet S, Murphy S, Anderson B, et al. Public finance of rotavirus vaccination in India and Ethiopia: an extended cost-effectiveness analysis. Vaccine 2013;31:4902-10.

49. Verguet S, Riumallo-Herl C, Gomez GB, et al. Catastrophic costs potentially averted by tuberculosis control in India and South Africa: a modelling study. Lancet Glob Health 2017;5:e112 3-e1132.

50. Baltussen R, Niessen L. Priority setting of health interventions: the need for multi-criteria decision analysis. Cost Eff Resour Alloc 2006;4:14.

51. Dhaliwal I, Duflo E, Glennerster R, et al. Comparative costeffectiveness analysis to inform policy in developing countries: a general framework with applications for education. Education Policy in Developing Countries 2013:285-338.

52. Ozawa S, Mirelman A, Stack ML, et al. Cost-effectiveness and economic benefits of vaccines in low- and middle-income countries: a systematic review. Vaccine 2012;31:96-108.

53. Ozawa S, Stack ML, Bishai DM, et al. During the 'decade of vaccines,' the lives of 6.4 million children valued at $\$ 231$ billion could be saved. Health Aff 2011;30:1010-20.

54. Portnoy A, Ozawa S, Grewal S, et al. Costs of vaccine programs across 94 low- and middle-income countries. Vaccine 2015;33 Suppl 1:A99-A108.

55. Stack ML, Ozawa S, Bishai DM, et al. Estimated economic benefits during the 'decade of vaccines' include treatment savings, gains in labor productivity. Health Aff 2011;30:1021-8. 